\title{
USP22 promotes the G1/S phase transition by upregulating FoxM1 expression via $\beta$-catenin nuclear localization and is associated with poor prognosis in stage II pancreatic ductal adenocarcinoma
}

\author{
ZHEN NING $^{1 *}$, AMAN WANG ${ }^{2 *}$, JINXIAO LIANG $^{1}$, YUNPENG XIE $^{3}$, \\ JIWEI LIU ${ }^{2}$, LU FENG $^{4}$, QIU YAN ${ }^{3}$ and ZHONGYU WANG ${ }^{1}$
}

\begin{abstract}
Departments of ${ }^{1}$ General Surgery, ${ }^{2}$ Oncology and ${ }^{3}$ Pathology, The First Affiliated Hospital of Dalian Medical University, Dalian 116011; ${ }^{4}$ Department of Biochemistry and Molecular Biology, Dalian Medical University, Dalian 116044, P.R. China
\end{abstract}

Received April 4, 2014; Accepted June 2, 2014

DOI: $10.3892 /$ ijo.2014.2531

\begin{abstract}
Ubiquitin-specific protease 22 (USP22), a newly discovered member of ubiquitin hydrolase family, exhibits a critical function in cell cycle progression and tumorigenesis. The forkhead box M1 (FoxM1) transcription factor plays a crucial role in cell proliferation, differentiation and transformation. However, the expression and functions of USP22 in pancreatic ductal adenocarcinoma (PDA) and whether FoxM1 is involved in USP22-mediated cell cycle regulation have not been studied. We examined the expression of USP22 and FoxM1 in 136 stage II PDA tissues by immunohistochemistry. Clinical significance was analyzed by multivariate Cox regression analysis, KaplanMeier curves and log-rank test. RT-PCR, western blot analysis, luciferase and immunofluorescence assays were used to investigate the molecular function of USP22 and FoxM1 in PDA fresh tissues and cell lines. USP22 and FoxM1 were significantly upregulated in PDA tissues compared with the paired normal carcinoma-adjacent tissues. A statistical correlation was observed between USP22 and FoxM1 expression. The expression of USP/FoxM1 and co-expression of both factors correlated with tumor size, lymph node metastasis and overall survival.
\end{abstract}

Correspondence to: Professor Qiu Yan, Department of Biochemistry and Molecular Biology, Dalian Medical University, Liaoning Provincial Core Lab of Glycobiology and Glycoengineering, Dalian 116044, P.R. China

E-mail: yanqiudl@126.com

Dr Zhongyu Wang, Department of General Surgery, The First Affiliated Hospital of Dalian Medical University, No. 222, Zhongshan Road, Dalian 116011, P.R. China

E-mail: wangzhongyudl@126.com

*Contributed equally

Key words: ubiquitin-specific protease 22, forkhead box M1, Wnt/ $\beta$-catenin, pancreatic ductal adenocarcinoma, prognosis, cell cycle
Multivariate Cox regression analysis revealed that the expression of USP22/FoxM1, especially the co-expression of both factors, is an independent, unfavorable prognostic factor. USP22 overexpression is accompanied by an increase in FoxM1 expression and USP22 increases FoxM1 expression to promote G1/S transition and cell proliferation through promoting $\beta$-catenin nuclear translocation in PDA cell lines. USP22 promotes the G1/S phase transition by upregulating FoxM1 expression via promoting $\beta$-catenin nuclear localization. USP22 and FoxM1 may act as prognostic markers and potential targets for PDA.

\section{Introduction}

In recent years, the mortality rate of pancreatic cancer has leapt to the fifth-highest position among all malignant tumors in developed countries, and the incidence of pancreatic cancer is still rising (1). Pancreatic ductal adenocarcinoma (PDA) that originates in glandular epithelium accounts for more than $90 \%$ of all malignant pancreatic tumors and exhibits a high degree of malignancy with a poor prognosis (2). To date, reliable biomarkers for the early diagnosis and effective treatment of PDA are lacking. Approximately $60 \%$ of PDA patients have advanced-stage disease at the time of diagnosis, and most patients die within a year after diagnosis (2). Although studies have identified the abnormal expression of certain oncogenes and tumor suppressor genes in PDA, such as the Kirsten rat sarcoma viral oncogene homolog (KRAS), epidermal growth factor receptor (EGFR), tumor protein 53 (TP53), Sma and Mad related family member 4/deleted in pancreatic cancer locus 4 (SMAD4/DPC4) and P16/cyclin-dependent kinase inhibitor 2A (P16/CDKN2A) (3), the mechanisms of PDA genesis and development remain unclear. A more profound understanding of the molecular mechanisms that underlie the biological behaviour of PDA is crucial to improve the prognosis of PDA patients.

As a newly discovered member of the ubiquitin hydrolase family, USP22 possesses deubiquitinating activity (4). USP22 is a key subunit of the human Spt-Ada-Gen5-acetyltransferase (hSAGA) transcriptional coactivator complex and can interact within the hSAGA complex to hydrolyses the ubiquitin conju- 
gated to histones $\mathrm{H} 2 \mathrm{~A}$ and $\mathrm{H} 2 \mathrm{~B}$, thus activating target gene transcription as mediated by alterations in levels of histone ubiquitylation (5). USP22 plays a key role in cell cycle regulation, embryo development and telomere homeostasis (5-7). Normal tissues express low levels of USP22, whereas UPS22 expression is significantly elevated in tumor tissues (4). Studies have shown that interfering with USP22 expression in tumor cells can arrest cell cycle progression in the G1 phase and inhibit tumor cell proliferation, leading to tumor cell apoptosis (5,8-10). Additionally, USP22 is closely related to metastatic potential, therapy resistance and solid tumor prognosis (11). Furthermore, USP22 is one of the genes comprising the 11-gene Polycomb/cancer stem cell signature (12). To date, the mechanism of the abnormal expression and regulation of USP22 remains unclear, and the relationship between UPS22 and pancreatic cancer has not been reported.

FoxM1 is a key member of the forkhead box family of transcription factors (13), which is characterised by a DNA-binding domain with a wing-shaped spiral structure (winged helix domain) (14). FoxM1 plays a critical role in regulating cell cycle and mitosis, and it is a key regulator of the G1/S and G2/M cell cycle transitions (15). FoxM1 regulates the expression of cell division cycle 25 homolog A (cdc25A) at the G1/S cell cycle checkpoint and controls the transcription of S-phase kinase-associated protein 2 (skp2) and cyclin-dependent kinase subunit 1 (cks1) $(16,17)$. Additionally, FoxM1 regulates the expression of $\mathrm{G} 2 / \mathrm{M}$ checkpoint genes such as cdc25B, cyclin $\mathrm{B}$, aurora-B, survivin, polo-like kinase 1 (PLK1) and the centromere proteins A/B/F (CENP A/B/F) $(14,18,19)$. FoxM1 is widely expressed in proliferating cells and is significantly upregulated in a variety of malignant tumors, including gastric cancer, non-small cell lung cancer, brain glioma, prostate cancer, cervical cancer and pancreatic cancer (20). Recent studies have found that FoxM1 is closely related to the occurrence and development of pancreatic cancer (21). Interference in FoxM1 expression inhibits the proliferation, invasion and metastasis of pancreatic cancer cells through the downregulation of cyclin B, cyclin D1, cyclin-dependent kinase $2(\mathrm{Cdk} 2)$, matrix metalloproteinase-2 (MMP-2), MMP-9 and vascular endothelial growth factor (VEGF) (22). Overexpression of FoxM1 activates mesenchymal cell markers and promotes the epithelial-mesenchymal transition (EMT) (23). Additionally, FoxM1 is associated with poor prognosis and therapy resistance in a variety of solid tumors, including pancreatic cancer (24-26).

The classical Wnt/ $\beta$-catenin signalling pathway is among the most widely studied signal transduction pathways in recent years. Upon abnormal Wnt pathway activation, Wnt ligands bind to cell surface frizzled/low density lipoprotein receptor-related protein (Fz/LRP) receptors, and $\beta$-catenin is then released from the degradation complex comprising Axin/denomatous polyposis coli (Axin/APC) and glycogen

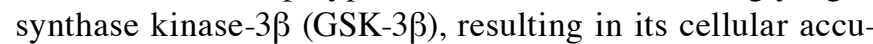
mulation and nuclear translocation. In the nucleus, $\beta$-catenin interacts with the $\mathrm{T}$ cell factor/lymphoid enhancer factor ( $\mathrm{TCF} / \mathrm{LEF})$ and regulates the expression of the downstream target genes c-Myc and cyclin D1, thus controlling cell cycle progression (27). Abnormal activation of the Wnt $/ \beta$-catenin signalling pathway plays an essential role in PDA tumorigenesis and metastasis $(28,29)$. Pasca et al observed varying degrees of $\mathrm{Wnt} / \beta$-catenin signalling pathway activation in
26 human pancreatic cancer cell lines and 3 different animal models of pancreatic cancer. Blockade of the Wnt/ $\beta$-catenin signalling pathway inhibits cell proliferation and promotes cell apoptosis (30). Zhang et al found that FoxM1 promoted the transfer of $\beta$-catenin to the nucleus and activated the Wnt pathway in glioma, thereby activating the expression of downstream target genes such as cyclin D1 and c-Myc and participating in tumorigenesis (31).

Although USP22 has been confirmed to be highly expressed in a variety of tumors and to be related to cell cycle regulation, the mechanism that underlies the role of USP22 has not been clearly reported. As a typical cell proliferation-associated transcription factor, the role of FoxM1 in cell cycle regulation has been acknowledged in recent years. However, whether FoxM1 is involved in USP22-mediated cell cycle regulation, as well as the relationship between USP22 and FoxM1, remains to be elucidated.

In the present study, we performed a systematic immunohistochemical analysis of USP22 and FoxM1 expression in PDA. Associations between USP22/FoxM1 expression, clinicopathological features and clinical outcome were investigated, respectively. As a correlation was found between UPS22 and FoxM1 expression in PDA tissues, the functional studies were carried out in PDA cell lines. We provide the first evidence that USP22 promoted the G1/S phase cell cycle transition and accelerated cell proliferation via upregulated FoxM1 expression. The $\beta$-catenin nuclear localization is required for USP22-mediated FoxM1 expression.

\section{Materials and methods}

Cell culture. The poorly differentiated human PDA cell line PANC-1 and the highly differentiated human PDA cell line CFPAC-1 were purchased from the cell bank of the Committee on Type Culture Collection of the Chinese Academy of Sciences (Shanghai, China) (32). PANC-1 cells were cultured in a 1:1 mixture of Dulbecco's modified Eagle's medium (DMEM) and F12 medium supplemented with 10\% fetal bovine serum (FBS; Invitrogen, Tokyo, Japan). CFPAC-1 cells were maintained in Iscove's modified Dulbecco's medium (IMDM) supplemented with 10\% FBS (Invitrogen). All cells were cultured in cell-culture flasks or Petri dishes in a humidified incubator at $37^{\circ} \mathrm{C}$ in an atmosphere of $5 \% \mathrm{CO}_{2}$.

Patients and tissue specimens. Paraffin-embedded specimens were obtained from 136 patients with stage II PDA who underwent surgical resection from January, 2002 to January, 2013 at the Department of General Surgery at the First Affiliated Hospital of Dalian Medical University. Patients with stage I, III and stage IV disease were excluded from this study because the case number was too small to be representative for these disease stages. One hundred and nine patients $(80.1 \%)$ underwent pancreaticoduodenectomy, 25 patients (18.4\%) underwent distal pancreatectomy, and 2 patients $(1.5 \%)$ received total pancreatectomy. Information on patient demographics (gender and age) and clinicopathologic features (tumor location, tumor size, resection margin, histological differentiation, lymph node metastasis and TNM stage) were obtained from clinical and pathological records (Table I). Histological PDA grading was based upon the World Health Organization grading system. 


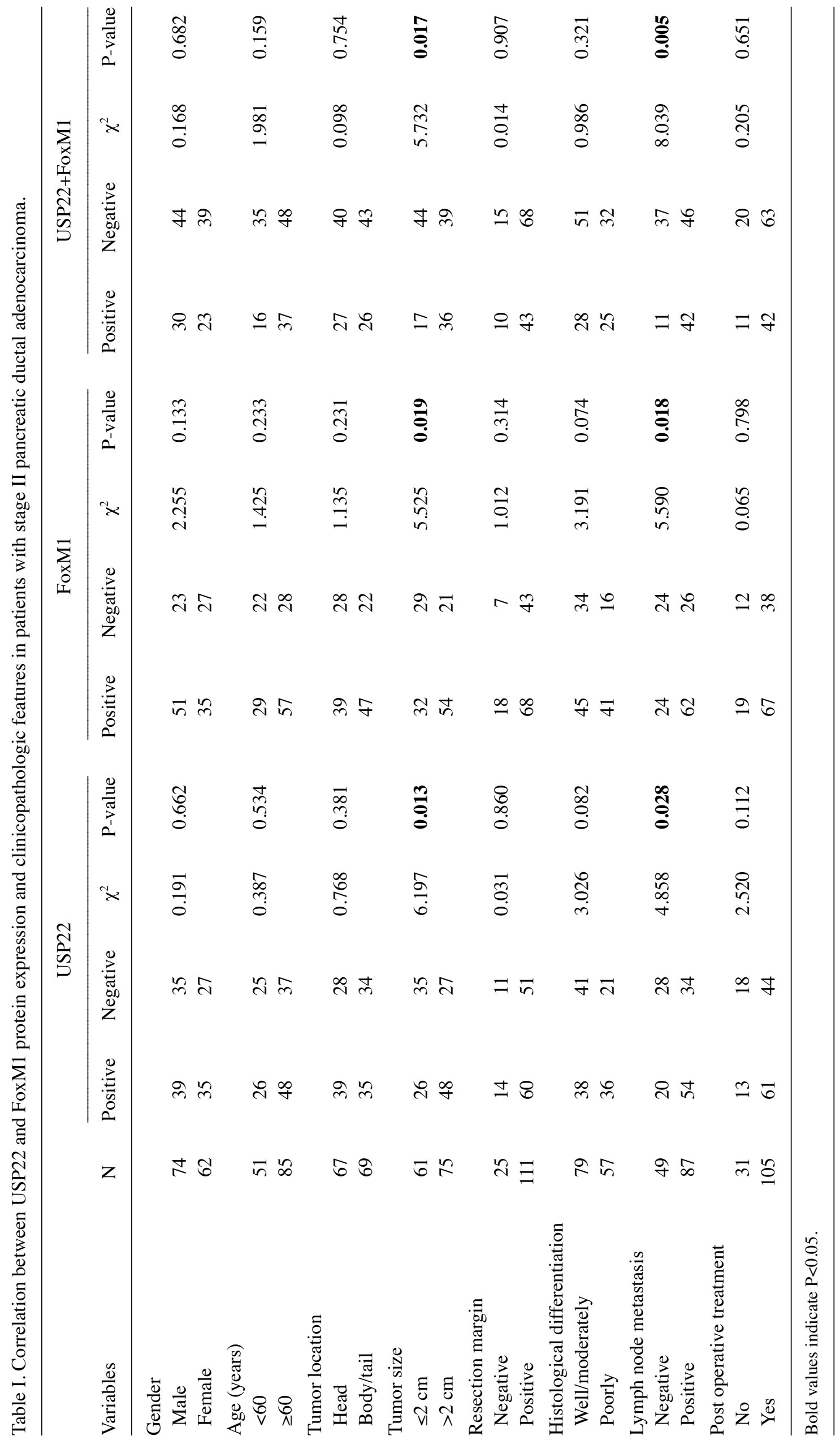


TNM stages were classified according to the criteria proposed by UICC/AJCC (2002). There were 74 male and 62 female patients with age ranging from 34 to 80 years (median age, 67 years). No neo-adjuvant radio- or chemotherapy was applied before surgical resection to any patient. Post-operatively, 82 patients $(60.3 \%)$ received adjuvant chemotherapy alone, 23 patients (16.9\%) received combined chemoradiation therapy and 31 patients $(22.8 \%)$ did not receive adjuvant therapy. All patients were followed up postoperatively until May, 2013 or death. Overall survival (OS) was defined as the interval between the dates of surgery and death. Ethical approval for the project was obtained from the First Affiliated Hospital of Dalian Medical University Research Ethics Committee. All fresh samples were confirmed by hematoxylin and eosin staining in frozen sections with histopathologic analysis; 5 pairs of PDA tissues and the paired normal carcinoma-adjacent tissues were dissected and separated to 2 parts for mRNA and protein studies.

Immunohistochemistry. USP22 and FoxM1 expression in the paraffin-embedded specimens was examined according to standard immunohistochemical methods (33). Anti-USP22 (ab4812; 1:200 dilution; Abcam, Cambridge, UK) and antiFoxM1 (SC-502; 1:50; Santa Cruz Biotechnology, Santa Cruz, CA, USA) antibodies were used as the primary antibodies. The percentage of positive cells was determined by counting 500 cells in five random areas per section. Nuclear immunostaining were evaluated using a semiquantitative assessment, which calculated the staining intensity and the percentage of positive cells. IHC staining was scored according to the following criteria: 0 , none of the cells stained; $1+, 1-20 \%$ of the cells stained; $2+, 20-50 \%$ of the cells stained; $3+, 50-100 \%$ of the cells stained. Furthermore, the expression levels of USP22 and FoxM1 were divided into the following two groups according to score: negative $(0,1+, 2+)$ and positive $(3+)$.

Plasmid preparation. The USP22 and $\beta$-catenin overexpression plasmids were designed and synthesised by Shanghai GenePharma Co., Ltd (Shanghai, China). Cells were cultured in Petri dishes to 80-90\% confluence and then transfected with Lipofectamine 2000 (Invitrogen) in strict accordance with the manufacturer's instructions. After transfection, the cells were cultured for 48 or $72 \mathrm{~h}$ before use in subsequent experiments.

siRNA analyses. Small interfering RNA (siRNA) for FoxM1 (5'-GCCGGAACAUGACCAUCAATT-3'), USP22 (5'-GCAG CTCACTATGAAGAAACT-3'), $\beta$-catenin (5'-AACAGTCTT ACCTGGACTCTG-3') and a negative control (NC) sequence (5'-GTTCTCCGAACGTGTCACGT-3') were purchased from Genepharma (Shanghai, China). According to the manufacturer's protocol, cells were transfected using Lipofectamine 2000 (Invitrogen). After transfection, the cells were cultured for 48 or $72 \mathrm{~h}$ before use in subsequent experiments.

CCK-8 assays. Cell viability in the treated cells was determined by using Cell Counting Kit-8 (CCK-8) kit (Dojindo Laboratories, Kumamoto, Japan) following the instructions outlined by the manufacturer. Cells were plated at a density of $3-5 \times 10^{3}$ cells/well with $200 \mu \mathrm{l}$ of medium in 96-well microtiter plates. After treatment, CCK- 8 solution $(10 \mu \mathrm{l})$ was added to each well and the plates were incubated at $37^{\circ} \mathrm{C}$ for $90 \mathrm{~min}$.
The absorbance of the cell suspension was measured with a microplate reader at a wavelength of $450 \mathrm{~nm}$.

Flow cytometry analysis. Cells pellets were washed with phosphate buffered saline and fixed/permeabilized with $50 \%$ ice-cold ethanol. Pellets were washed and resuspended in $50 \mu \mathrm{g} / \mathrm{ml}$ ribonuclease A and $62.5 \mu \mathrm{g} / \mathrm{ml}$ propidium iodide. Samples were analysed on the Becton-Dickinson FACSCalibur (Becton-Dickinson, Franklin Lakes, NJ, USA). The percentages of cells in various phases of the cell cycle were quantified using the ModFit LT Version 3.0 program (Verity Software House, Topsham, ME, USA). The error bars were derived from the SD of multiple experiments.

$R T-P C R$. Total RNA was extracted with the TRIzol reagent according to the manufacturer's protocol and then it was reverse transcribed into cDNA using RNA PCR kit (AMV) version 3.0. cDNA was amplified by PCR using the specific primer for USP22, FoxM1 or $\beta$-actin as an internal control. The sequences of the upstream and downstream primers were as follows: USP22 forward, 5'-CATGACCCCTTTCATGGCCT-3' and reverse, 5'-GATGTTCTGGTGACGGGTGT-3'; FoxM1 forward, 5'-GGC TCCCGCAGCATCAAGCA-3' and reverse, 5'-TGTTCCGGC GGAGCTCTGGA-3'; $\beta$-actin forward, 5'-ATCTGGCACCAC ACCTTCACAATGAGCTGCG-3' and reverse, 5'-CGTCATAC TCCTGCTTGCTGATCCACATCTGC-3', respectively. PCR analysis was performed under the following conditions: denaturation at $94^{\circ} \mathrm{C}$ for $5 \mathrm{~min}$, followed by 30 cycles of denaturation for $40 \mathrm{sec}$ at $94^{\circ} \mathrm{C}$, annealing for $30 \mathrm{sec}$ at $52^{\circ} \mathrm{C}$ for USP $22,57^{\circ} \mathrm{C}$ for FoxM1, $58^{\circ} \mathrm{C}$ for $\beta$-actin and extension for $40 \mathrm{sec}$ at $72^{\circ} \mathrm{C}$. The amplified products were analyzed by $1.0 \%$ agarose gel electrophoresis, followed by ethidium bromide staining. Band intensities were measured using BioImaging systems (UVP, Labworks ${ }^{\mathrm{TM}}$, ver 4.6).

Western blot analysis. Proteins were separated by SDS-PAGE and transferred to nitrocellulose membrane (Bio-Rad, Hercules, CA, USA). Membranes were blocked in a buffer (TBS: $50 \mathrm{mM}$ Tris- $\mathrm{HCl}, 150 \mathrm{mM} \mathrm{NaCl}, \mathrm{pH} 7.4)$ containing $5 \%$ bovine serum albumin and $0.1 \%$ Tween-20, followed by incubation with the primary antibodys USP22 (ab4812, 1:2,000, Abcam), FoxM1 (SC-502, 1:200, Santa Cruz Biotechnology), cyclin D1 (60186-1-lg, 1:100), p21 (10355-1-AP, 1:100), p27 (10567-1-AP, 1:100), cdk4 (11026-1-AP, 1:500), cdk6 (14052-1-AP, 1:500, all from Proteintech, Chicago, IL, USA), $\beta$-catenin (SC-7963, 1:500, Santa Cruz Biotechnology), Axin2 (EPR2005-2, 1:2,000), LEF (EP2030Y, 1:2,000, both from Abcam), c-Myc (10057-1-AP, 1:200) and LMNB1 (12987-1-AP, 1:1,000) or $\beta$-actin (20536-1-AP, $1: 2,000$, all from Proteintech) diluted in the same buffer. The immunoreactive proteins were visualized using the ECL western blot analysis system (Bio-Rad), and densitometric analysis was performed using the Image Pro-Plus software.

$\beta$-catenin/TCF transcription reporter assay. Briefly, $1 \times 10^{5}$ cells were seeded per well in a 24 -well plate before transient transfection with the construct TOPflash or FOPflash reporter plasmid (Millipore, Billerica, MA, USA). TOPflash comprised three copies of the TCF/LEF sites upstream of a thymidine kinase (TK) promoter and the Firefly luciferase gene. FOPflash comprised three mutated copies of TCF/LEF sites and were 
used as a control for measuring non-specific activation of the reporter. All transfections were performed using $0.8 \mu \mathrm{g}$ of TOPflash or FOPflash plasmid and $2 \mu$ l lipofectamine 2000. To normalise the transfection efficiency in reporter assays, the cells were cotransfected with $0.02 \mu \mathrm{g}$ of an internal control reporter plasmid, containing Renilla reniformis luciferase driven by the TK promoter. At $24 \mathrm{~h}$ after TOPflash or FOPflash transfection, the luciferase assay was performed with the Dual Luciferase Assay System kit (Promega Corp., Madison, WI, USA). Relative luciferase activity was reported as the fold induction after normalization for transfection efficiency.

Immunofluorescence. Pancreatic cancer cells were seeded onto cover slips, fixed with $4 \%$ paraformaldehyde and permeabilized with $0.3 \%$ Triton $\mathrm{X}-100$ for $10 \mathrm{~min}$. Slides were blocked with $1 \%$ bovine serum albumin and incubated with USP22, FoxM1 or $\beta$-catenin antibodies overnight at $4^{\circ} \mathrm{C}$. After washing in PBS, the cells were stained with secondary antibodies and incubated for $1 \mathrm{~h}$ at room temperature, followed by nuclear counterstaining with DAPI.

Statistical analysis. Statistical analyses were performed using SPSS software package version 17.0. The Pearson $\chi^{2}$ test or Fisher's exact test was used to compare qualitative variables. OS was estimated by Kaplan-Meier curves and the curves were compared using the log-rank test. OS was analysed using the Cox proportional hazards model for univariate and multivariate analyses. The hazard ratios (HRs) between prognostic groups and the $95 \%$ confidence intervals were analysed. The quantitative data derived from three independent experiments are expressed as means $( \pm$ SD). Unpaired Student's t-tests were used to analyze between repeated group differences. $\mathrm{P}<0.05$ was considered statistically significant.

\section{Results}

USP22 and FoxM1 expression in PDA tissues and the paired normal carcinoma-adjacent tissues. The expression of USP22 and FoxM1 was analysed by immunohistochemistry in PDA tissues and the paired normal carcinoma-adjacent tissues $(\mathrm{n}=136)$. USP22 and FoxM1 staining in PDA tissues appeared as brown particles which were mainly localized within the nuclei and cytoplasm, with minute staining in the cell membrane as well as some scattered infiltrated lymphocytes (Fig. 1B and C). No or minimal fluorescent staining showed in the normal carcinoma-adjacent tissues (Fig. 1A). This finding is consistent with those of earlier reports. The incidence of positive expression was 54.4\% (74/136) for USP22 and 63.2\% (86/136) for FoxM1 in PDA tissues and 8.8\% (12/136) for USP22 and $7.4 \%(10 / 136)$ for FoxM1 in the normal tissues. In addition, $53(39.0 \%)$ PDA tissues showed a co-positive expression of USP22/FoxM1. Compared with the normal tissues, PDA tissues expressed significantly high USP22 and FoxM1 $(\mathrm{P}<0.001$, Fig. 1D). Additionally, a statistical correlation was observed between USP22 and FoxM1 expression ( $\mathrm{r}=0.221, \mathrm{P}=0.01)$.

Correlation between USP22/FoxM1 expression and clinicopathologic features. The co-distribution of PDA with a positive or negative USP22/FoxM1 expression in relation to clinicopathologic features is shown in Table I. USP22 expres- sion was significantly associated with tumor size (0.013) and lymph node metastasis $(\mathrm{P}=0.028)$. FoxM1 expression was significantly associated with tumor size $(\mathrm{P}=0.019)$ and lymph node metastasis $(\mathrm{P}=0.018)$. Furthermore, a co-positive expression of USP22/FoxM1 was significantly associated with lymph node metastasis $(\mathrm{P}=0.017)$ and TNM stage $(\mathrm{P}=0.005)$.

Correlation between USP22/FoxM1 expression and patient survival. We assessed the prognostic value of USP22 and FoxM1 expression on survival in PDA patients. Kaplan-Meier analysis demonstrated that PDA patients with USP22, FoxM1 and co-expression USP22/FoxM1 had a significantly poorer OS compared to the patients with negative expression (log-rank $\mathrm{P}=0.007 ; \mathrm{P}=0.027$; and $\mathrm{P}=0.002$, respectively, Fig. 2). In univariate analysis, USP22 (HR, 3.227; 95\% CI, 1.877-6.979; $\mathrm{P}=0.007$, Table II), FoxM1 (HR, 1.837; 95\% CI, 1.185-4.993; P=0.027; Table II), co-expression USP22/FoxM1 (HR, 2.608; 95\% CI, 1.659-5.959; $\mathrm{P}=0.002$, Table II), tumor size, margin and lymph node metastasis were significant prognostic factors of PDA. In multivariate analysis of Table III model A, USP22 (adjusted HR, 1.944; 95\% CI, 1.492-2.998; $\mathrm{P}=0.044$ ), margin (adjusted HR, 1.331; 95\% CI, 1.171-1.994; $\mathrm{P}=0.033$ ) and lymph node metastasis (adjusted HR, 3.229; 95\% CI, 1.573-6.988; $\mathrm{P}=0.020$ ) were independent prognostic factors of survival. Table III model B showed that positive co-expression of USP22/FoxM1 (adjusted HR, 1.728; 95\% CI, 1.275-2.684; $\mathrm{P}=0.012$ ), margin (adjusted HR, 1.827; 95\% CI, 1.167-2.192; $\mathrm{P}=0.027$ ) and lymph node metastasis (adjusted HR, 2.931; 95\% CI, 1.476-4.990; $\mathrm{P}=0.023$ ) were determined as independent prognostic factors.

USP22/FoxM1 expression in fresh-frozen PDA tissues and cell lines. To further confirm the afore-mentioned results, RT-PCR and western blot analyses were performed on 5 pairs of PDA fresh-frozen tumor tissues and the paired normal carcinoma-adjacent tissues. The results showed that both USP22 and FoxM1 expression were significantly higher in PDA tissues than the paired normal carcinoma-adjacent tissues (Fig. 3A and B). USP22 and FoxM1 expression were also examined in PDA cell lines PANC-1 and CFPAC-1. The results showed that expression of USP22 and FoxM1 was significantly elevated in the poorly differentiated PANC-1 cell line in comparison with the highly differentiated CFPAC-1 cell line (Fig. 3C and D).

USP22 regulates the G1/S phase transition and affects the expression of G1 phase-related proteins through FoxM1 in PDA cell lines. To investigate the role of USP22 and its possible underlying mechanism in PDA tumorigenesis, USP22 plasmid or FoxM1-siRNA was transfected in both the poorly differentiated PANC-1 cell line and highly differentiated CFPAC-1 cell line. The CCK- 8 proliferation assay showed that USP22 overexpression significantly stimulated the proliferation of both cell lines and the interference of FoxM1 expression produced significant inhibition of the proliferation of both cell lines. However, the depletion of FoxM1 expression, caused by FoxM1-siRNA interference, in the USP22-overexpressing PANC-1 and CFPAC-1 cell lines abolished the USP22 overexpression-stimulated cell proliferation (Fig. 4C and D). Additionally, flow cytometry revealed that USP22 overexpression increased the G1/S transition rate, resulting in a significant 

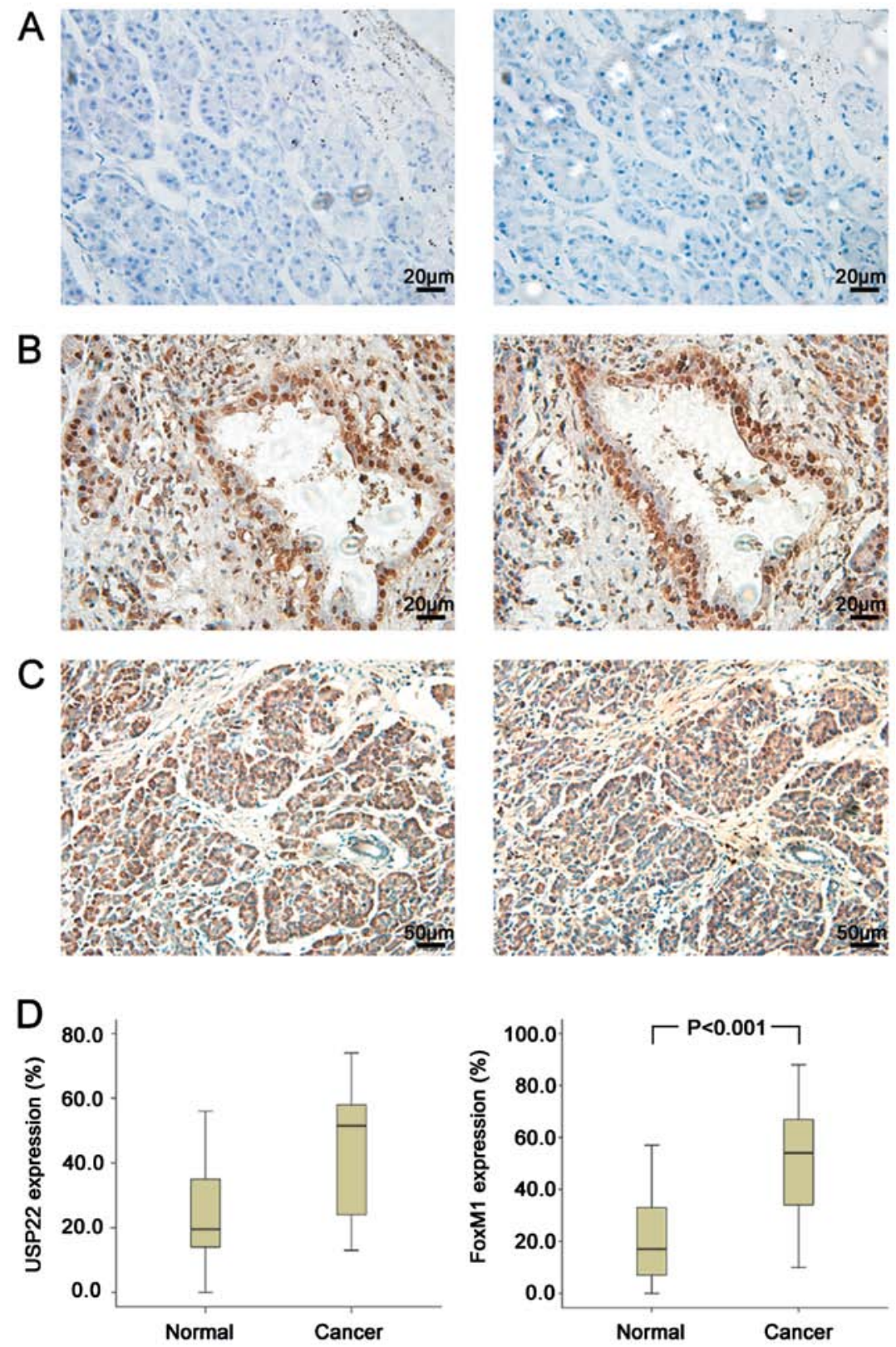

Figure 1. Detection of USP22 and FoxM1 immunoreactivity in normal carcinoma-adjacent tissues and PDA. (A) Normal carcinoma-adjacent tissues showed no or weak immunoreactions for USP22 (left) and FoxM1 (right), which was identified as negative expression in this study. Original magnification, $\mathrm{x} 400$. (B) In contrast to the situation in the normal carcinoma-adjacent tissues, strong immunostaining of USP22 (left) and FoxM1 (right), which were primarily localized in the nuclei, were observed in the cancer cells. Original magnification, x400. (C) Strong immunostaining of USP22 (left) and FoxM1 (right), which were localized in the cytoplasm, were observed in the cancer cells. Original magnification, $\mathrm{x} 200$. (D) IHC analysis of proteins expression in normal tissues and cancer tissues ( $\mathrm{n}=136$ ). Compared with the normal tissues, cancer tissues expressed significantly high USP22 ( $\mathrm{P}<0.001)$ and FoxM1 $(\mathrm{P}<0.001)$.
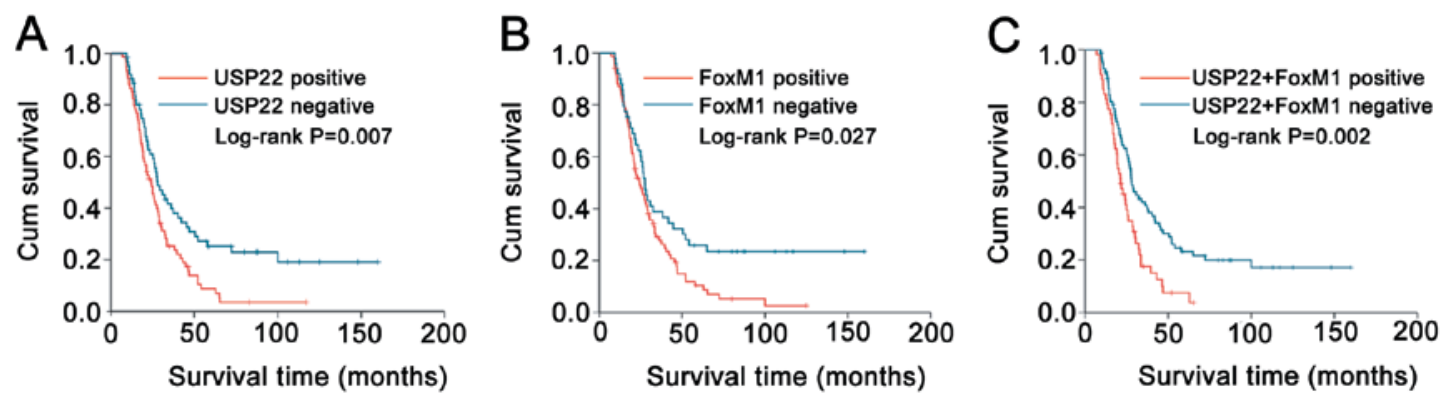

Figure 2. Kaplan-Meier survival curves of OS in patients with PDA according to USP22 and FoxM1 expression. (A) Positive expression of USP22 was significantly associated with poor OS ( $\mathrm{P}=0.007)$. (B) Positive expression of FoxM1 was significantly associated with poor OS ( $\mathrm{P}=0.027)$. (C) Co-positive expression of USP22 and FoxM1 was significantly associated with poor OS $(\mathrm{P}=0.002)$. 
Table II. Univariate analyses for survival in patients with stage II pancreatic ductal adenocarcinoma.

\begin{tabular}{lcccr}
\hline & & \multicolumn{2}{c}{$95 \% \mathrm{CI}$} \\
\cline { 3 - 4 } Variables & Hazard ratio & Lower & Upper & P-value \\
\hline Gender & 1.206 & 0.831 & 1.750 & 0.324 \\
Age & 0.094 & 0.791 & 1.618 & 0.439 \\
Tumor location & 0.825 & 0.569 & 2.195 & 0.309 \\
Tumor size & 2.317 & 1.099 & 4.380 & $\mathbf{0 . 0 1 5}$ \\
Margin & 1.924 & 1.266 & 2.987 & $\mathbf{0 . 0 1 8}$ \\
Histological differentiation & 1.402 & 0.863 & 3.041 & 0.078 \\
Lymph node metastasis & 5.905 & 1.853 & 9.959 & $\mathbf{0 . 0 0 1}$ \\
Post operative treatment & 0.753 & 0.591 & 1.920 & 0.097 \\
USP22 & 3.227 & 1.877 & 6.979 & $\mathbf{0 . 0 0 7}$ \\
FoxM1 & 1.737 & 1.185 & 4.993 & $\mathbf{0 . 0 2 7}$ \\
USP22+FoxM1 & 2.608 & 1.659 & 5.959 & $\mathbf{0 . 0 0 2}$ \\
\hline
\end{tabular}

CI, confidence interval; bold values indicate $\mathrm{P}<0.05$.

Table III. Multivariate analyses for survival in patients with stage II pancreatic ductal adenocarcinoma.

\begin{tabular}{|c|c|c|c|c|}
\hline \multirow[b]{2}{*}{ Variables } & \multirow[b]{2}{*}{ Hazard ratio } & \multicolumn{2}{|c|}{$95 \% \mathrm{CI}$} & \multirow[b]{2}{*}{ P-value } \\
\hline & & Lower & Upper & \\
\hline \multicolumn{5}{|l|}{ Model A } \\
\hline Tumor size & 1.348 & 0.797 & 2.004 & 0.138 \\
\hline Margin & 1.331 & 1.171 & 1.994 & 0.033 \\
\hline Lymph node metastasis & 3.229 & 1.573 & 6.988 & 0.020 \\
\hline USP22 & 1.944 & 1.492 & 2.998 & 0.044 \\
\hline FoxM1 & 1.270 & 0.713 & 2.830 & 0.316 \\
\hline \multicolumn{5}{|l|}{ Model B } \\
\hline Tumor size & 1.369 & 0.623 & 1.930 & 0.118 \\
\hline Margin & 1.827 & 1.167 & 2.192 & 0.027 \\
\hline Lymph node metastasis & 2.931 & 1.476 & 4.990 & 0.023 \\
\hline USP22+FoxM1 & 1.728 & 1.275 & 2.684 & 0.012 \\
\hline
\end{tabular}

CI, confidence interval; bold values indicate $\mathrm{P}<0.05$.

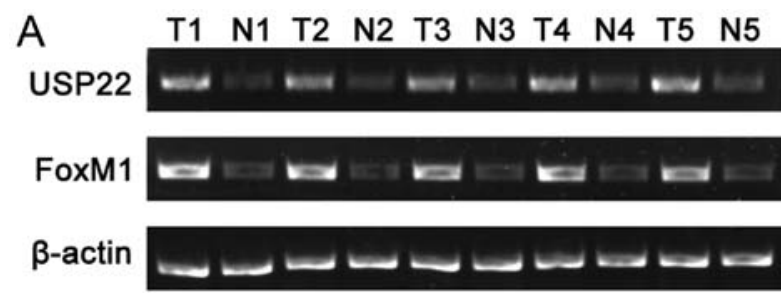

$\begin{array}{llllllllllll}B & \text { T1 } & \text { N1 } & \text { T2 } & \text { N2 } & \text { T3 } & \text { N3 } & \text { T4 } & \text { N4 } & \text { T5 } & \text { N5 }\end{array}$

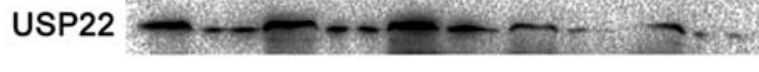

FoxM1

$\beta$-actin
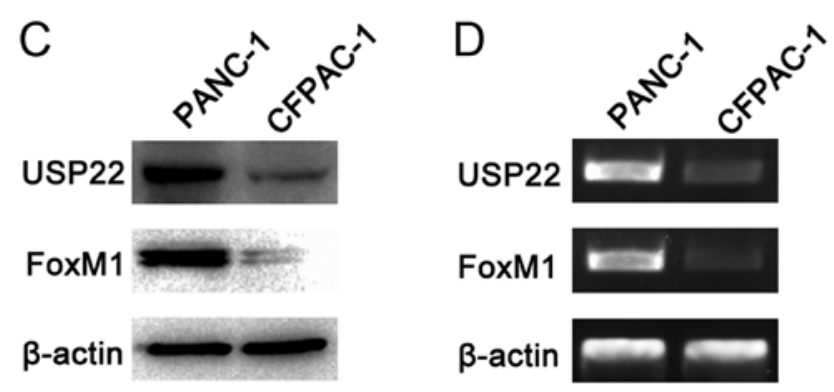

Figure 3. USP22 and FoxM1 expression in fresh-frozen PDA tissues and cell lines. (A and B) RT-PCR and western blot analysis of USP22 and FoxM1 in the 26 pairs PDA fresh-frozen tumor tissues and the paired normal carcinomaadjacent tissues. (C and D) RT-PCR and western blot analysis of USP22 and FoxM1 in the poorly differentiated PANC-1 cell line in comparison with the highly differentiated CFPAC-1 cell line. 

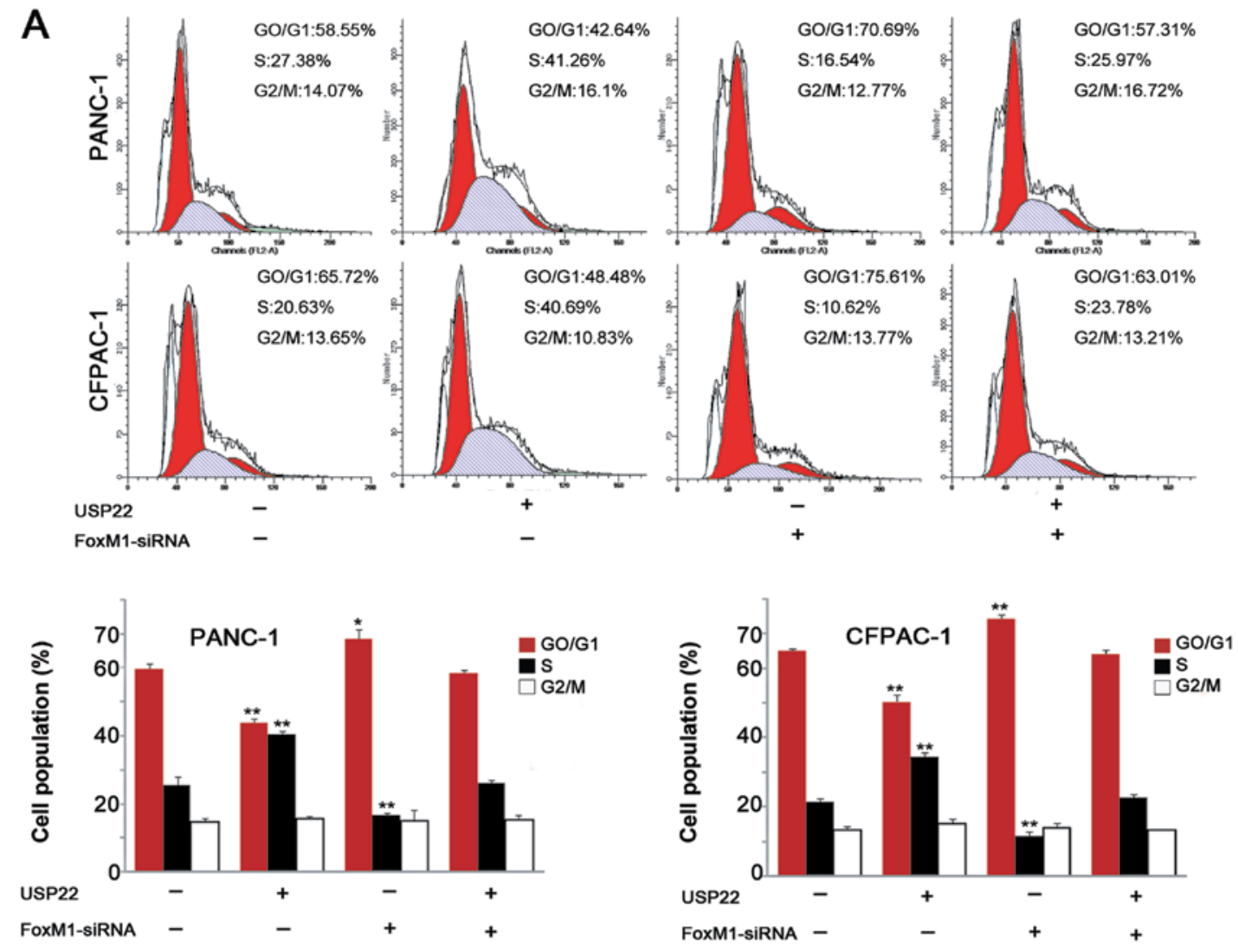

B
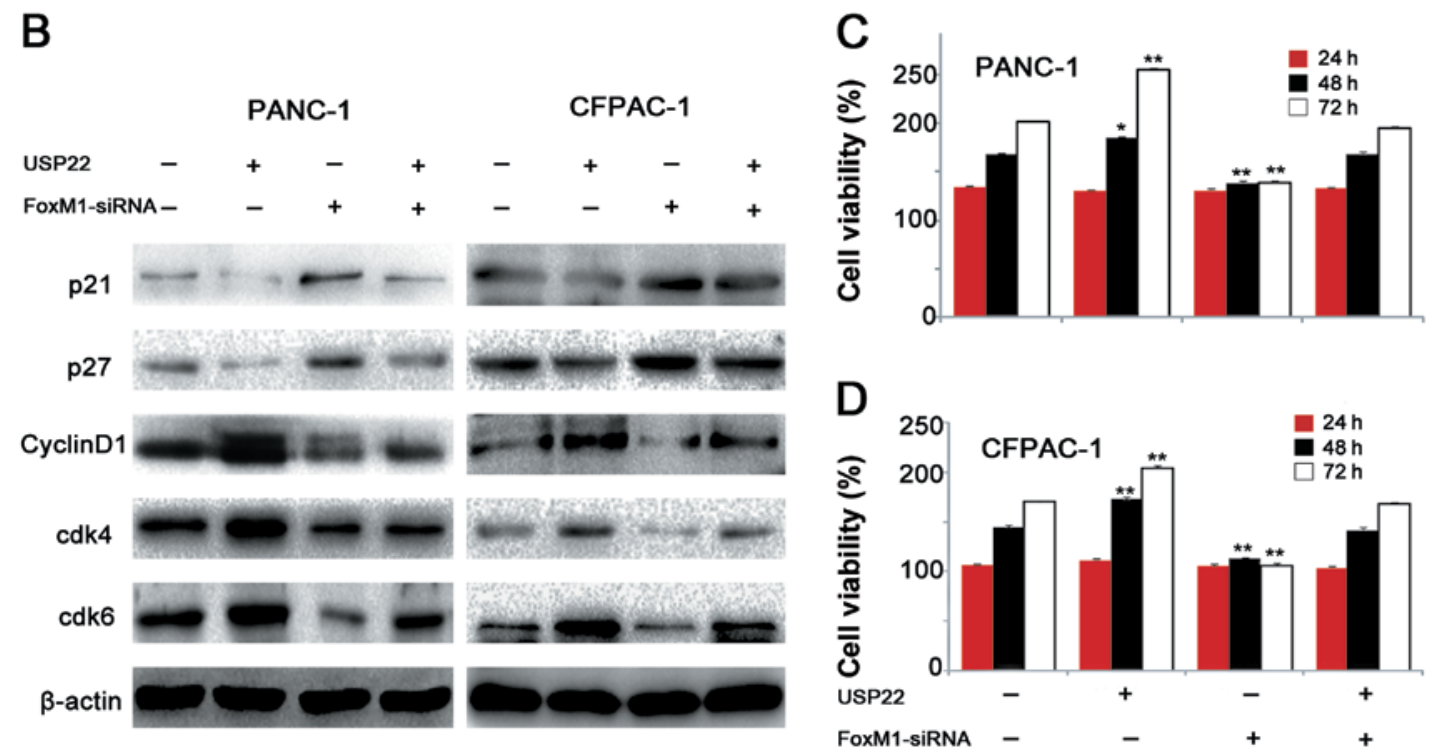

Figure 4. USP22 regulates the G1/S phase transition and affects the expression of G1 phase-related proteins through FoxM1 in PDA cell lines. (A) Flow cytometry analysis was performed on the PDA cell lines PANC-1 and CFPAC-1 that were transfected by USP22, FoxM1-siRNA or USP22+FoxM1-siRNA. Values are mean \pm SD for triplicate samples. (B) Cellular levels of p21, p27, cyclin D1, cdk4, cdk6 in the PDA cell lines PANC-1 and CFPAC-1 that were transfected by USP22, FoxM1-siRNA or USP22+FoxM1-siRNA. (C and D) CCK-8 analysis was performed on the PDA cell lines PANC-1 and CFPAC-1 which were transfected by USP22, FoxM1-siRNA or USP22+FoxM1-siRNA. Values are mean \pm SD for triplicate samples. "P<0.05, compared with control. ${ }^{* * *} \mathrm{P}<0.01$, compared with control.

decrease in the proportion of G1 phase cells and an increase in the proportions of S phase. Upon FoxM1 downregulation by RNAi, USP22 overexpression no longer elicited significant changes in cell cycle progression in either cell line (Fig. 4A). Further studies showed that USP22 overex- pression resulted in decreased $\mathrm{p} 21$ and $\mathrm{p} 27$ expression in both cell lines, which were accompanied by the increased cyclin D1 levels. Similarly, the expression levels of cdk4 and cdk6 were also increased. FoxM1 depletion abolished the USP22-induced changes in G1 phase-related protein 
A
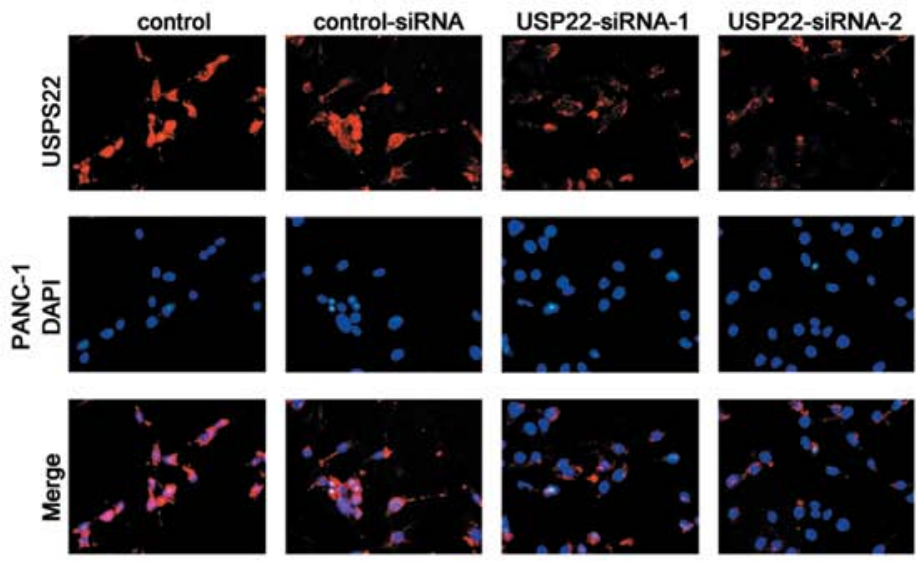

B
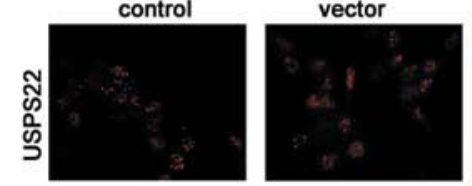

USP22-1

USP22-2
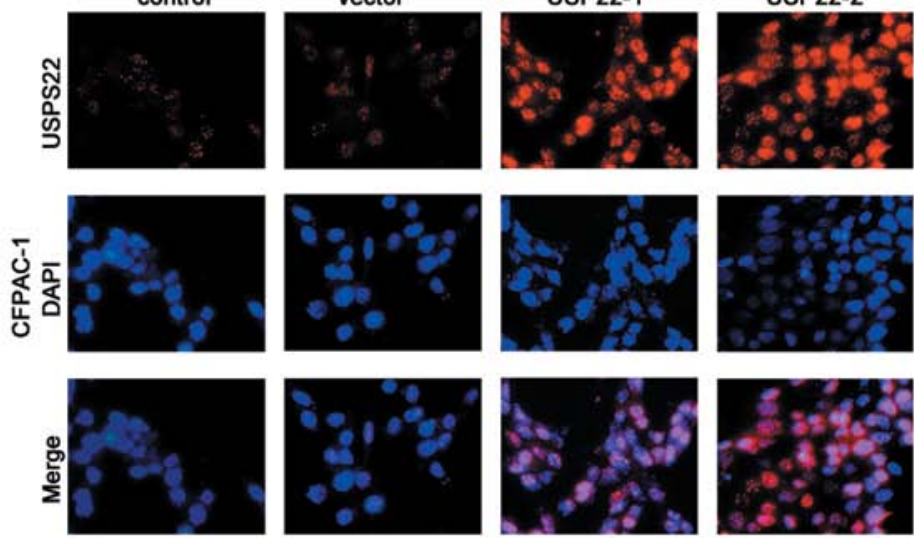

C
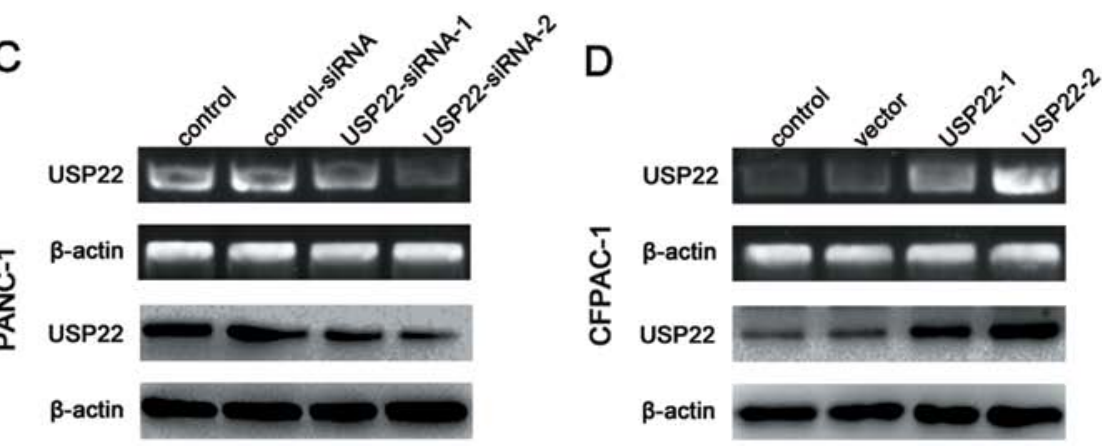

Figure 5. USP22 expression in PDA cell lines transfected by USP22-siRNA or USP22 overexpressing plasmid. (A) IF staining for USP22 (red) and nuclei (DAPI, blue) was performed on PANC-1 cells that were transfected by control-siRNA, USP22-siRNA-1 (50 nM) or USP22-siRNA-2 (150 nM). (B) IF staining for USP22 (red) and nuclei (DAPI, blue) was performed on CFPAC-1 cells that were transfected by vector, USP22-1 (2 $\mu \mathrm{g})$ and USP22-2 (10 $\mu \mathrm{g})$. (C and D) RT-PCR and western blot analysis of USP22 in PANC-1 cells that were transfected by control-siRNA, USP22-siRNA-1 (50 nM) or USP22siRNA-2 $(150 \mathrm{nM})$ and CFPAC-1 cells that were transfected by vector, USP22-1 $(2 \mu \mathrm{g})$ or USP22-2 $(10 \mu \mathrm{g})$.

expression in both cell lines (Fig. 4B). These results suggested that USP22 promoted the G1/S phase transition and affected G1 phase-related protein expression in PDCA cell lines via the upregulation of FoxM1 expression.

USP22 expressionaffects FoxM1 expression and Wnt/ $\beta$-catenin pathway activation. We used different concentrations of the USP22 plasmids or USP22-siRNA to achieve the different degrees of downregulation of USP22 in the PANC-1 cell line which originally expressed rather high levels of USP22, as well as the different degrees of upregulation of USP22 in the CFPAC-1 cell line which expressed relatively low levels of endogenous USP22. The results of RT-PCR, western blot and immunofluorescence staining analyses confirmed the success of the above-described transfection efforts (Fig. 5). The immunofluorescence experiments also showed that USP22 expression was mainly nuclear (Fig. 5A and B). The USP22 downregulation in the PANC-1 cell line resulted in reduction of the expression of $2 \mathrm{Wnt} / \beta$-catenin signalling pathway marker proteins, Axin2 and lymphoid enhancer-binding factor-1 (LEF-1), as well as the downstream target protein c-Myc (Fig. 6E). Using a luciferase reporter plasmid, we also confirmed a decrease in $\mathrm{Wnt} / \beta$-catenin signalling activity (Fig. 6F). In the CFPAC-1 cell line, the USP22 upregulation led to increases in the expression of Axin2, LEF-1 and the downstream target protein c-Myc (Fig. 6E). The luciferase 
A
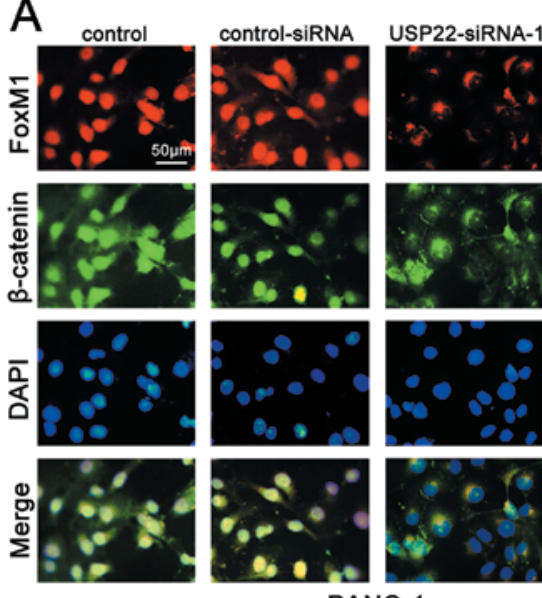

PANC-1
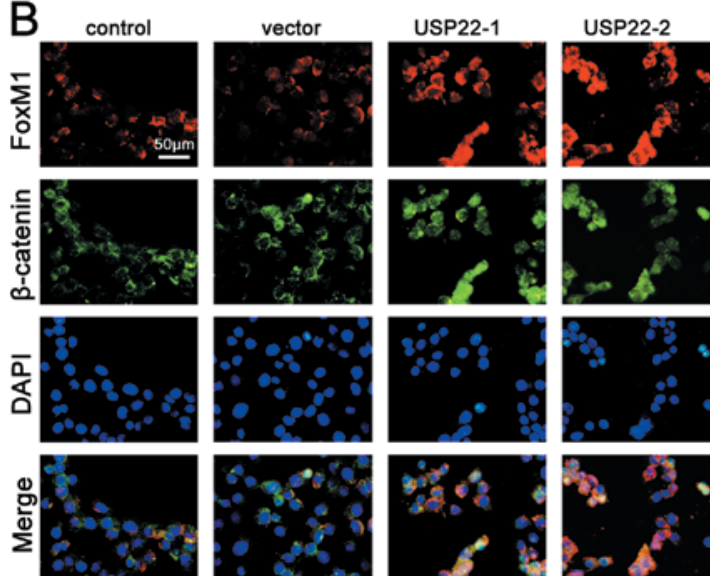

CFPAC-1
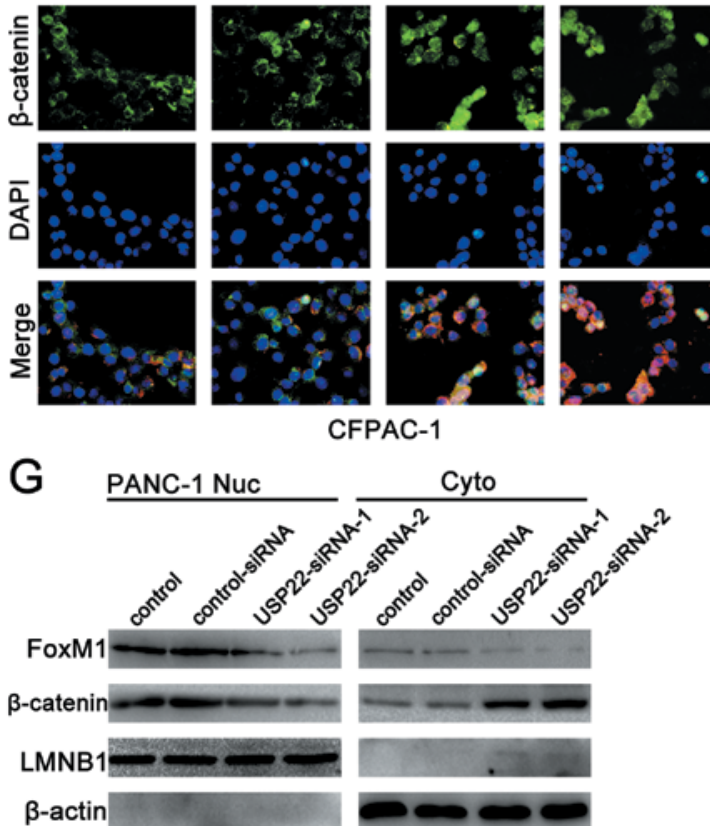

C
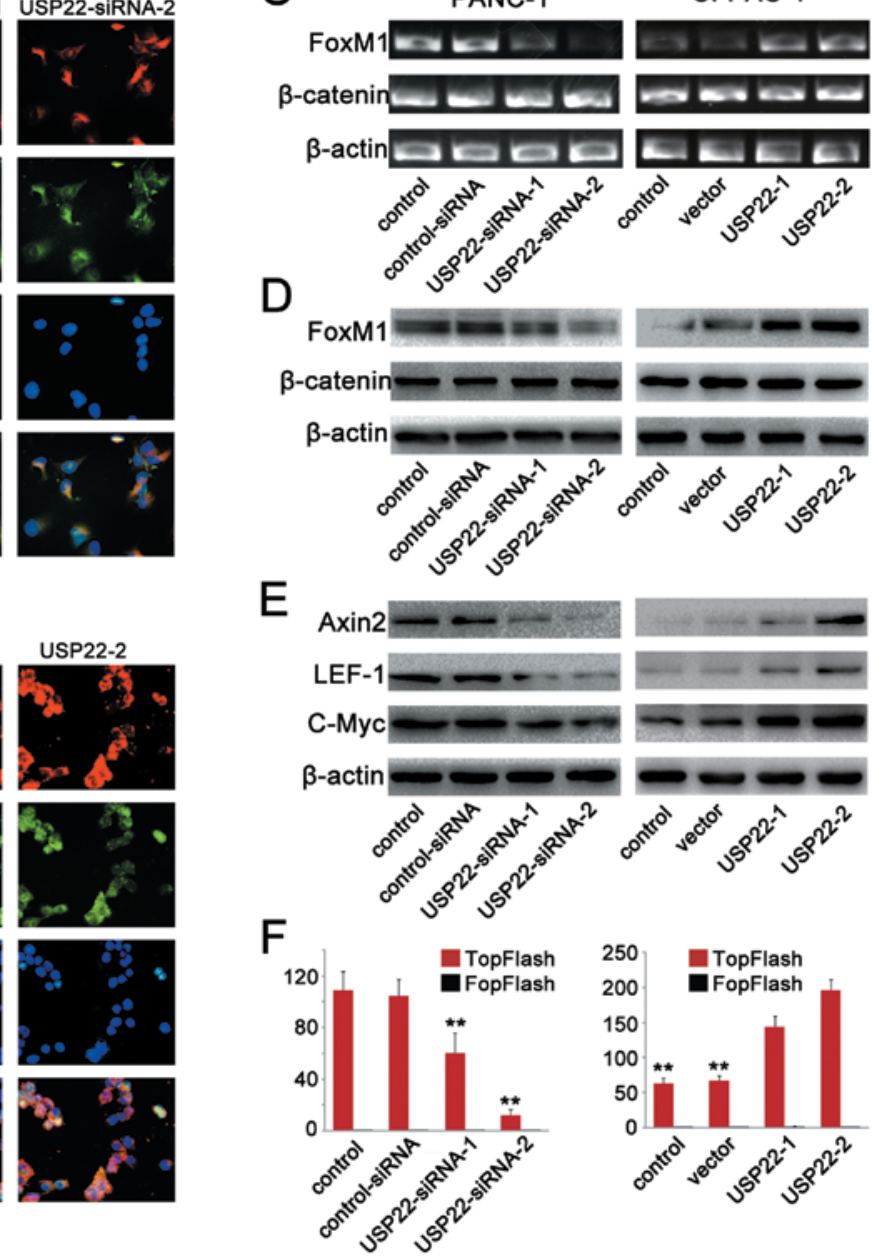

$\mathrm{H}$

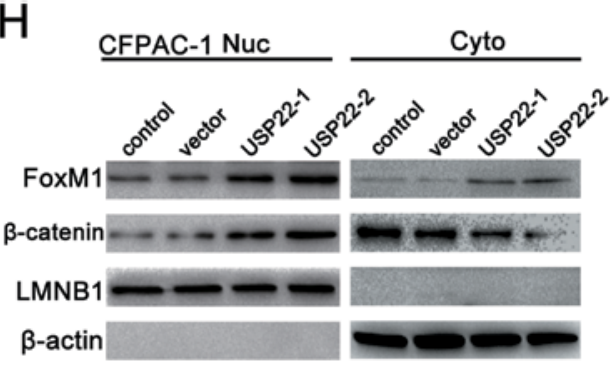

Figure 6. USP22 expression affects FoxM1 expression and Wnt/ $\beta$-catenin pathway activation. (A) Triple IF staining for FoxM1 (red), $\beta$-catenin (green) and nuclei (DAPI, blue) was performed on PANC-1 cells that were transfected by control-siRNA, USP22-siRNA-1 (50 nM) or USP22-siRNA-2 (150 nM). (B) Triple IF staining for FoxM1 (red), $\beta$-catenin (green) and nuclei (DAPI, blue) was performed on CFPAC-1 cells that were transfected by vector USP22-1 $(2 \mu \mathrm{g})$ or USP22-2 $(10 \mu \mathrm{g})$. (C and D) RT-PCR and western blot analysis of FoxM1 and $\beta$-catenin in PANC-1 cells that were transfected by controlsiRNA, USP22-siRNA-1 (50 nM) or USP22-siRNA-2 (150 nM) (left panel) and CFPAC-1 cells that were transfected by vector, USP22-1 (2 $\mu$ g) or USP22-2 $(10 \mu \mathrm{g})$ (right panel). (E) Cellular levels of Axin2, c-Myc and LEF-1 in PANC-1 cells that were transfected by control-siRNA, USP22-siRNA-1 (50 nM) or USP22-siRNA-2 (150 nM) (left panel) and CFPAC-1 cells that were transfected by vector, USP22-1 (2 $\mu \mathrm{g})$ or USP22-2 (10 $\mu \mathrm{g})$ (right panel). (F) Activities of TOP-Flash and FOP-Flash in PANC-1 cells that were transfected by control-siRNA, USP22-siRNA-1 (50 nM) or USP22-siRNA-2 (150 nM) (left panel) and CFPAC-1 cells that were transfected by vector, USP22-1 (2 $\mu \mathrm{g})$ or USP22-2 (10 $\mu \mathrm{g})$ (right panel). (G) Cytoplasmic and nuclear levels of FoxM1 and $\beta$-catenin in PANC-1 cells that were transfected by control-siRNA, USP22-siRNA-1 (50 nM) or USP22-siRNA-2 (150 nM). (H) Cytoplasmic and nuclear levels of FoxM1 and $\beta$-catenin in CFPAC-1 cells that were transfected by vector USP22-1 (2 $\mu \mathrm{g})$ or USP22-2 (10 $\mu \mathrm{g})$.

reporter assay also confirmed an increase in $\mathrm{Wnt} / \beta$-catenin signalling activity (Fig. 6F).

To prove that USP22 regulates FoxM1 expression via the Wnt/ $\beta$-catenin signalling pathway, western blot and immunofluorescence analyses were performed. The results showed that the USP22 downregulation in PANC-1 cells led to a reduction in nuclear $\beta$-catenin expression, as well as an elevation in cytoplasmic $\beta$-catenin expression. Reduction was observed in both nuclear and cytoplasmic FoxM1 expression (Fig. 6A, C, D and $\mathrm{G})$. In the CFPAC-1 cell line, the USP22 upregulation led to an increase in nuclear $\beta$-catenin expression and a reduction in cytoplasmic $\beta$-catenin expression. Concurrently, increases were observed in both nuclear and cytoplasmic FoxM1 expression (Fig. 6B, C, D and H). These results indicated that in PDA cell 
A
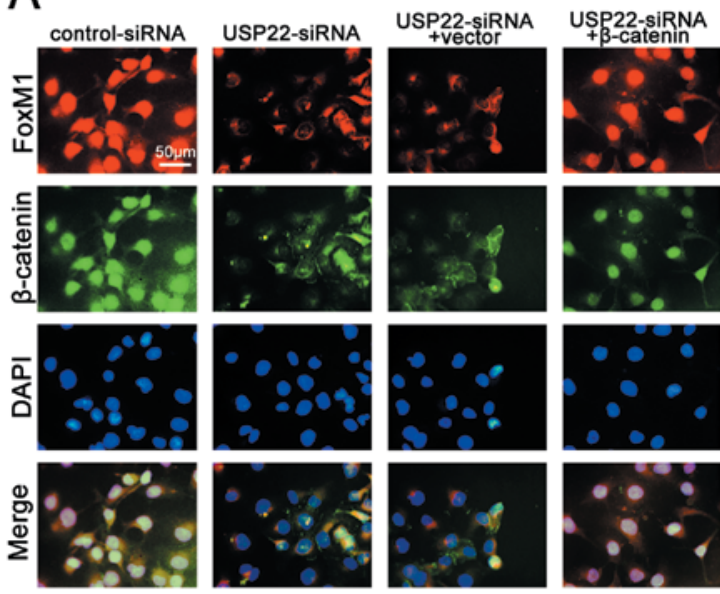

PANC-1
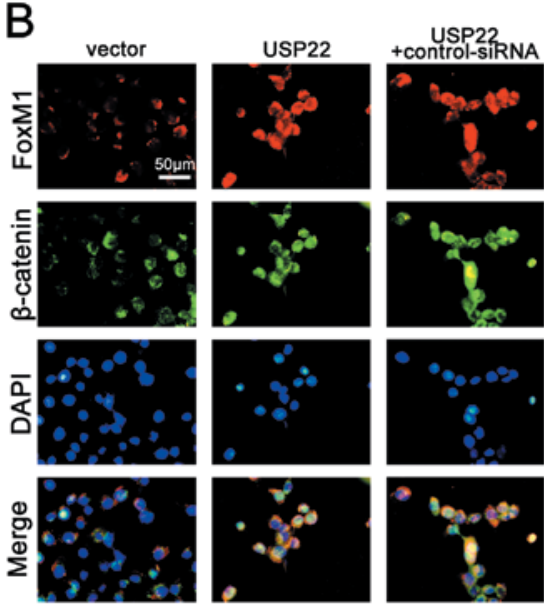

CFPAC-1
C

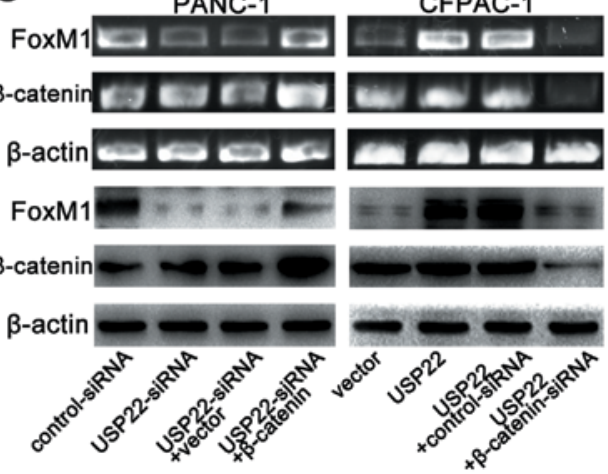

D
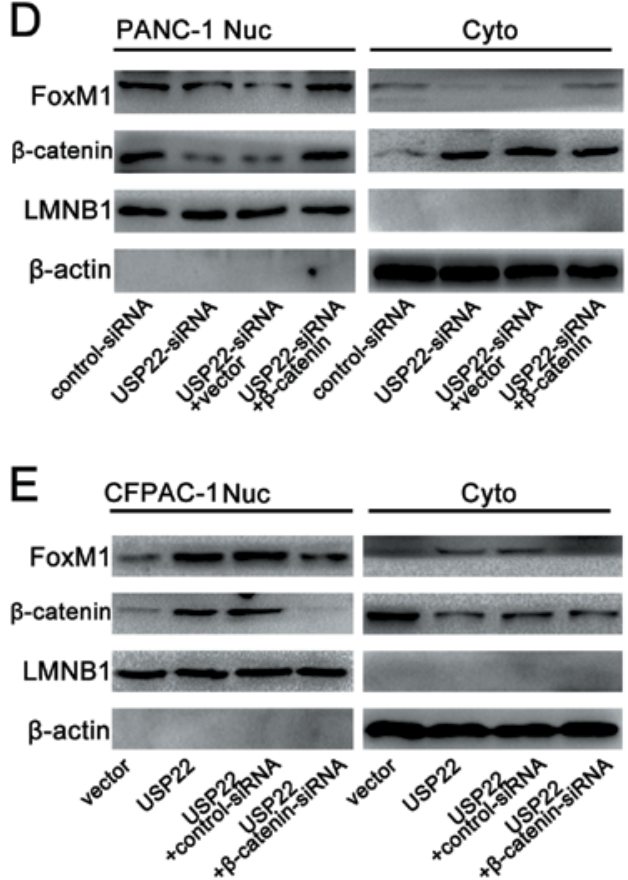

Figure 7. $\beta$-catenin is required for USP22-mediated FoxM1 expression. (A) Triple IF staining for FoxM1 (red), $\beta$-catenin (green) and nuclei (DAPI, blue) was performed in PANC-1 cells that were transfected by control-siRNA, USP22-siRNA, USP22-siRNA+vector or USP22-siRNA+ $\beta$-catenin. (B) Triple IF staining for FoxM1 (red), $\beta$-catenin (green) and nuclei (DAPI, blue) was performed in CFPAC-1 cells that were transfected by vector, USP22, USP22+control-siRNA or USP22+ $\beta$-catenin-siRNA. (C) RT-PCR and western blot analysis of FoxM1 and $\beta$-catenin in PANC- 1 cells that were transfected by control-siRNA, USP22-siRNA, USP22-siRNA+vector or USP22-siRNA+ $\beta$-catenin (left panel) and CFPAC-1 cells that were transfected by vector, USP22, USP22+control-siRNA or USP22+ $\beta$-catenin-siRNA (right panel). (D) Cytoplasmic and nuclear levels of FoxM1 and $\beta$-catenin in PANC-1 cells that were transfected by control-siRNA, USP22-siRNA, USP22-siRNA+vector or USP22-siRNA+ $\beta$-catenin. (E) Cytoplasmic and nuclear levels of FoxM1 and $\beta$-catenin in CFPAC-1 cells that were transfected by vector USP22, USP22+control-siRNA or USP $22+\beta$-catenin-siRNA.

lines, USP22 expression significantly altered FoxM1 expression via the $\mathrm{Wnt} / \beta$-catenin signalling pathway.

\section{$\beta$-catenin nuclear localization is required for USP22-mediated} FoxM1 expression. The nuclear transfer of $\beta$-catenin is believed to be directly responsible for elevated $\mathrm{Wnt} / \beta$-catenin signalling pathway activity. The $\beta$-catenin expression levels in the nucleus directly represent the level of $\mathrm{Wnt} / \beta$-catenin signalling pathway activity. $\beta$-catenin depletion or overexpression has been widely used to trigger corresponding changes in Wnt/ $\beta$-catenin signalling pathway activity. In additional experiments on the PANC-1 cell line, we found that when $\beta$-catenin expression was upregulated with the $\beta$-catenin overexpressing plasmid, USP22 knockdown with USP22siRNA failed to induce significant changes in either nuclear or cytoplasmic FoxM1 expression (Fig. 7A, C and D). In the CFPAC-1 cell line, when $\beta$-catenin expression was disrupted with $\beta$-catenin-siRNA, USP22 overexpression failed to trigger significant changes in either nuclear or cytoplasmic FoxM1 expression (Fig. 7B, C and E). These results strongly suggest that in PDA cell lines, USP22-mediated FoxM1 expression depends on the nuclear localization of $\beta$-catenin.

\section{Discussion}

In an analysis of mRNA levels in a variety of tumor tissues in 2005, Glinsky et al identified 11 overexpressed genes in tumor tissues that can serve as death-from-cancer signature genes, including USP22, BUB1, HEC1/KNTC2, CCNB1, Ki67, Gbx2, FGFR2, ANK3, CES, BMI-1 and RNF2 (12). The study 
suggests that USP22 overexpression may be correlated with short-term tumor recurrence, distant metastasis and treatment resistance (11). A number of studies have confirmed that USP22 overexpression is present in various solid tumors such as papillary thyroid, breast, non-small cell lung, esophageal, gastric and colon cancer, and is closely related to the metastatic potential and prognosis of tumors (33-38). However, no study has reported its expression in pancreatic cancer.

USP22, one of the 11 death-from-cancer signature genes, functions as a cell cycle regulator and plays an important role in cell cycle progression (11). hSAGA is a transcription cofactor complex that recruits the transcriptional complex to the promoter of its target genes to activate gene transcription through specific amino acid covalent modifications of histone tails, such as acetylation, methylation and deubiquitination $(39,40)$. USP22, a subunit of hSAGA, can cause deubiquitination of histone $\mathrm{H} 2 \mathrm{~A}$ and $\mathrm{H} 2 \mathrm{~B}$ and acetylation of histone $\mathrm{H} 4$ (41). hSAGA is involved in the transcription of Myc target genes. The amino-terminal of c-Myc protein carries two conserved domains, MbI and MbII, which combine with hSAGA to initiate the transcription of c-Myc target genes. Studies have shown that USP22 knockdown using shRNA resulted in a decline in the expression of Myc target genes including CDCA7, cyclin D2, ODC, CAD and MTA1. ChIP assays also confirm that USP22 binds to the promoter regions of Myc target genes and triggers the transcription of these genes. In addition, downregulation of USP22 expression slows the proliferation of Myc-overexpressing cells and arrests the cells in the G1 phase, leading to a lower cloning efficiency (5). These results suggest that USP22 can promote cell proliferation and mediate malignant cell behavior via Myc-regulated target genes. Moreover, USP22 can also modulate the expression of the tumor suppressor gene p21 by altering the ubiquitination level of its upstream element FBP1, thereby affecting cell cycle progression (42).

A member of the Fox transcription factor family, FoxM1 is specifically expressed in proliferating cells and is absent in terminally differentiated cells. FoxM1 can initiate target gene transcription, mediate the transcription of cell cycle-related genes, and promote cell proliferation by suppressing $\mathrm{Cdk}$ inhibitors, such as p21 and p27, and the phosphatase activity of some cyclins (e.g., cyclin A1, cyclin B1 and cyclin D1) and Cdk activators Cdc25a and Cdc25b (17-19,43-45). First, FoxM1 upregulates the expression of $\mathrm{CdK}$ inhibitors p21 and p27 in the nucleus by controlling the transcription of two important subunits Skp2 and Cks1 in the ubiquitin ligase complex SCF, thereby promoting DNA replication in S phase (46). Current studies have shown that numerous cell cycle regulators, such as E2F, cyclin D1, cyclin E, cyclin A, cyclin B, CDC25B, p27, p21 and p53, are all substrates of the ubiquitin proteasome pathway (47-52). Wang et al showed that FoxM1 activation mediates the degradation of G1/S transition regulators p27 and p21 by activating Skp2-Cksl ubiquitin ligase. As p27 and p21 are CDK inhibitors, decreased expression of p27 and p21 will inevitably lead to reduced inhibition of cell cycle, which helps cells move beyond the G1/S phase checkpoint and enter S phase to synthesize DNA and make preparations for cell proliferation $(46,53)$. In addition, FoxM1 also regulates the transcription of many mitosis-related genes, including cyclin B1, Cdc25B, pololike kinase 1 (PLK1), aurora B kinase, survivin, centromere protein A (CENPA) and CENPB (54). Previous studies have shown that FoxM1 expression is abnormally high in a variety of malignancies such as gastric, non-small cell lung cancer, glioma and cervical cancer and can be used as a prognostic marker $(24,25,55,56)$. Xia et al also confirmed that FoxM1 is overexpressed in pancreatic cancer and can be used as an independent prognostic factor (26), but the exact mechanism has not been examined.

Currently, no study has reported the role of USP22 in pancreatic cancer. Given that both USP22 and FoxM1 are involved in cell cycle progression, this leads us to question whether USP22 and FoxM1 interact in cell cycle regulation and whether the two factors are involved in the development and progression of pancreatic cancer.

To address these issues, we determined the expression of USP22 and FoxM1 in 136 PDA tissues and 42 PDA adjacent normal tissues using immunohistochemistry. The results showed that the expression of USP22 and FoxM1 was abnormally upregulated in the PDA tissue and that up to $39.0 \%$ of patients with high expression of USP22 also had FoxM1 overexpression, exhibiting a significant correlation between the expression levels of USP22 and FoxM1. Detection in fresh tissues also supported the above results. This suggests that there may be some interplay between USP22 and FoxM1 in pancreatic cancer. Further analysis revealed that USP22/FoxM1 overexpression is closely associated with the clinical and pathological features of PDA patients and can be used as an independent prognostic factor for PDA patients. In particular, patients with positive co-expression of USP22/FoxM1 have a worse prognosis. These results indicate that USP22 and FoxM1 may be jointly involved in the development and progression of PDA. However, it remains unknown whether and how USP22 interacts with FoxM1 in pancreatic cancer.

With the above question in mind, we selected two PDA cell lines for study. The results showed that the expression of USP22 and FoxM1 was significantly higher in poorly differentiated PANC-1 cell line than in highly differentiated CFPAC-1 cell line. To determine the role of USP22 in the proliferation and cell cycle of PDA cells, we upregulated USP22 expression in both cell lines and found faster G1/S phase transition and significantly accelerated cell proliferation. Next, we upregulated USP22 expression and knocked down FoxM1 expression in both cell lines. The results showed that with FoxM1 downregulation, USP22 upregulation alone caused no significant change in G1/S transition and cell proliferation. This indicates that FoxM1 plays a key role in the regulation by USP22 of G1/S transition and cell proliferation. Moreover, we found that USP22 upregulation was accompanied by p21 and p27 downregulation as well as upregulation of cell cycle-related proteins cyclin D1, cdk4 and cdk6; USP22 upregulation combined with FoxM1 knockdown did not cause significant change in the expression of the above proteins. This suggests that FoxM1 plays an important role in the regulation by USP22 of G1 phase related proteins. Therefore, our study indicates that FoxM1 is a key factor essential for the regulation by USP22 of G1/S transition.

USP22 and FoxM1 play a role in the transcriptional regulation of a variety of oncogenes and tumor suppressor genes (e.g., c-Myc, SIRT1, BMI-1). Previous studies have shown that USP22 promotes tumor growth by enhancing c-Myc-mediated gene transcription (5). FoxM1 can also help tumor cells pass 
through checkpoints and promote tumor cell proliferation through direct transcriptional activation of the TATA box in human c-Myc transcription promoters P1 and P2 (57). SIRT1 upregulation is involved in tumorigenesis in a variety of tumor cells by promoting tumor cell proliferation and inhibiting apoptosis (58). Lin et al revealed that as part of the SAGA complex, USP22 can directly regulate the expression of SIRT1 via deubiquitination and affect the activity of SIRT1 target genes, thereby regulating DNA repair and apoptosis (6). Zhu et al demonstrated that FoxM1 directly associates with SIRT1 promoter, increases the transcriptional activity of SIRT1, and promote glioma cell proliferation (59). As a component of PcG protein, BMI-1 determines to a certain extent the proliferation potential of cancer stem cells (60). Previous research showed high expression of USP22 and BMI-1 in gastric and colorectal cancer $(33,38)$. Liu et al found that USP22 can regulate cell cycle in colon cancer through BMI-1-mediated pRb, P53 and Akt/GSK3 $\beta$ pathways (61). Li et al showed that BMI-1 is one of the downstream target genes of FoxM1. FoxM1 overexpression can attenuate the activity of p19 (Arf)-p53 pathway, downregulate $\mathrm{p} 53$ and $\mathrm{p} 21$ gene expression, and activate c-Myc-mediated BMI-1 gene expression (62). These studies suggest that USP22 and FoxM1 share common target genes and may work in synergy to participate in development and progression of tumors.

The Wnt signaling pathway plays an important role in embryonic development and tumorigenesis. $\beta$-catenin is an important component in the classical Wnt signaling pathway. c-Myc is the second target in the Wnt signaling pathway. Upon its translocation to the nucleus, $\beta$-catenin reacts with transcription factors in the Tcf/Lef family to form $\beta$-catenin/Tcf complexes, which then activate target genes such as c-Myc, c-jun and cyclin D1, leading to abnormal cell proliferation and differentiation and tumor formation (63). Heiser et al found that sustained activation of $\beta$-catenin in mice can lead to pancreatic intraepithelial neoplasia and eventual tumor formation (64-66). Zhang et al showed that inhibition of the Wnt pathway can significantly delay the development of pancreatic intraepithelial neoplasia (67). Ripka et al and Griesmann et al suggest that the Wnt pathway enhances the proliferation, invasion and metastasis activity of pancreatic cancer cells and is involved in epithelial-to-mesenchymal transformation of pancreatic cancer cells $(68,69)$. Accordingly, substantial evidence indicates that the Wnt/ $\beta$-catenin signaling pathway plays an important role in the development and progression of pancreatic cancer (30). Furthermore, Zhang et al showed that FoxM1 binds to $\beta$-catenin and promotes the nuclear translocation of the latter, hence increasing the activity of the Wnt/ $\beta$-catenin pathway (31). This finding is corroborated by Bowman et al (70). These studies also strongly suggest that the activation of the $\mathrm{Wnt} / \beta$-catenin signaling pathway, especially $\beta$-catenin nuclear translocation, may play an important role in the regulation by USP22 of FoxM1.

To test the above hypothesis, we used different plasmid concentrations to create a descending gradient of USP22 expression in the PANC-1 cell line and an ascending gradient of USP22 expression in the CFPAC-1 cell line. With the gradient change in USP22 expression, a similar trend change also occurred in Wnt/ $\beta$-catenin signaling pathway activity and FoxM1 expression in the nucleus and cytoplasm in the two cell lines. Further analysis showed that after $\beta$-catenin expression was upregulated in the PANC-1 cell line, even USP22 expression was significantly decreased, there was no significant change in the expression of FoxM1. After the $\beta$-catenin expression was knocked down in the CFPAC-1 cell line, even significant USP22 upregulation failed to cause a significant increase in FoxM1 expression. These results confirm our hypothesis that USP22 regulates FoxM1 expression through the $\mathrm{Wnt} / \beta$-catenin signaling pathway, especially $\beta$-catenin nuclear translocation.

In summary, our immunohistochemical analysis demonstrated that varying levels of USP22 and FoxM1 overexpression are present in PDA tissue and that the expression of both factors, especially the co-expression of the factors, is an independent prognostic factor of PDA. In vitro investigation showed that USP22 overexpression is accompanied by an increase in FoxM1 expression and that USP22 increases FoxM1 expression to promote G1/S transition and cell proliferation through promoting $\beta$-catenin nuclear translocation in PDA cell lines. These results demonstrate for the first time that USP22 and FoxM1 are jointly involved in the development and progression of pancreatic cancer and are promising new targets for pancreatic cancer targeted therapy.

\section{Acknowledgements}

This study was supported by the National Natural Science Foundation of China Research grant (no. 30870719 to Z.W., no. 30672753 to J.L.) and China 973 grant (no. 2012CB822100 to Q.Y.).

\section{References}

1. Jemal A, Bray F, Center MM, Ferlay J, Ward E and Forman D: Global cancer statistics. CA Cancer J Clin 61: 69-90, 2011.

2. Hidalgo M: Pancreatic cancer. N Engl J Med 362: 1605-1617, 2010.

3. Singh P, Srinivasan R and Wig JD: Major molecular markers in pancreatic ductal adenocarcinoma and their roles in screening, diagnosis, prognosis, and treatment. Pancreas 40: 644-652, 2011.

4. Lee HJ, Kim MS, Shin JM, Park TJ, Chung HM and Baek KH: The expression patterns of deubiquitinating enzymes, USP22 and Usp22. Gene Expr Patterns 6: 277-284, 2006.

5. Zhang XY, Varthi M and Sykes SM, et al: The putative cancer stem cell marker USP22 is a subunit of the human SAGA complex required for activated transcription and cell-cycle progression. Mol Cell 29: 102-111, 2008.

6. Lin Z, Yang $\mathrm{H}$ and Kong Q, et al: USP22 antagonizes p53 transcriptional activation by deubiquitinating Sirt1 to suppress cell apoptosis and is required for mouse embryonic development. Mol Cell 46: 484-494, 2012.

7. Atanassov BS, Evrard YA and Multani AS, et al: Gen5 and SAGA regulate shelterin protein turnover and telomere maintenance. Mol Cell 35: 352-364, 2009.

8. Xu H, Liu YL, Yang YM and Dong XS: Knock-down of ubiquitin-specific protease 22 by micro-RNA interference inhibits colorectal cancer growth. Int J Colorectal Dis 27: 21-30, 2012.

9. Lv L, Xiao XY, Gu ZH, Zeng FQ, Huang LQ and Jiang GS: Silencing USP22 by asymmetric structure of interfering RNA inhibits proliferation and induces cell cycle arrest in bladder cancer cells. Mol Cell Biochem 346: 11-21, 2011.

10. Ling SB, Sun DG, Tang B, et al: Knock-down of USP22 by small interfering RNA interference inhibits HepG2 cell proliferation and induces cell cycle arrest. Cell Mol Biol (Noisy-le-grand) 58: L1803-L1808, 2012.

11. Glinsky GV: Genomic models of metastatic cancer: functional analysis of death-from-cancer signature genes reveals aneuploid, anoikis-resistant, metastasis-enabling phenotype with altered cell cycle control and activated Polycomb Group $(\mathrm{PcG})$ protein chromatin silencing pathway. Cell Cycle 5: 1208-1216, 2006. 
12. Glinsky GV, Berezovska O and Glinskii AB: Microarray analysis identifies a death-from-cancer signature predicting therapy failure in patients with multiple types of cancer. J Clin Invest 115: 1503-1521, 2005.

13. Jackson BC, Carpenter C, Nebert DW and Vasiliou V: Update of human and mouse forkhead box (FOX) gene families. Hum Genomics 4: 345-352, 2010.

14. Laoukili J, Kooistra MR and Bras A, et al: FoxM1 is required for execution of the mitotic programme and chromosome stability. Nat Cell Biol 7: 126-136, 2005.

15. Wierstra I and Alves J: FOXM1, a typical proliferation-associated transcription factor. Biol Chem 388: 1257-1274, 2007.

16. Luscher-Firzlaff JM, Lilischkis R and Luscher B: Regulation of the transcription factor FOXM1c by Cyclin E/CDK2. FEBS Lett 580: 1716-1722, 2006.

17. Major ML, Lepe R and Costa RH: Forkhead box M1B transcriptional activity requires binding of $\mathrm{Cdk}$-cyclin complexes for phosphorylation-dependent recruitment of p300/CBP coactivators. Mol Cell Biol 24: 2649-2661, 2004.

18. Wang X, Hung NJ and Costa RH: Earlier expression of the transcription factor HFH-11B diminishes induction of p21(CIP1/WAF1) levels and accelerates mouse hepatocyte entry into $\mathrm{S}$-phase following carbon tetrachloride liver injury. Hepatology 33: 1404-1414, 2001.

19. Wang X, Krupczak-Hollis K, Tan Y, Dennewitz MB, Adami GR and Costa RH: Increased hepatic Forkhead Box M1B (FoxM1B) levels in old-aged mice stimulated liver regeneration through diminished p27Kip1 protein levels and increased Cdc25B expression. J Biol Chem 277: 44310-44316, 2002.

20. Laoukili J, Stahl M and Medema RH: FoxM1: at the crossroads of ageing and cancer. Biochim Biophys Acta 1775: 92-102, 2007.

21. Wang Z, Ahmad A, Banerjee S, et al: FoxM1 is a novel target of a natural agent in pancreatic cancer. Pharm Res 27: 1159-1168, 2010.

22. Wang Z, Banerjee S, Kong D, Li Y and Sarkar FH: Down-regulation of Forkhead Box M1 transcription factor leads to the inhibition of invasion and angiogenesis of pancreatic cancer cells. Cancer Res 67: 8293-8300, 2007.

23. Bao B, Wang Z, Ali S, et al: Over-expression of FoxM1 leads to epithelial-mesenchymal transition and cancer stem cell phenotype in pancreatic cancer cells. J Cell Biochem 112 2296-2306, 2011.

24. Li X, Qiu W, Liu B, et al: Forkhead box transcription factor 1 expression in gastric cancer: FOXM1 is a poor prognostic factor and mediates resistance to docetaxel. J Transl Med 11: 204, 2013.

25. Wang Y, Wen L, Zhao SH, Ai ZH, Guo JZ and Liu WC: FoxM1 expression is significantly associated with cisplatin-based chemotherapy resistance and poor prognosis in advanced non-small cell lung cancer patients. Lung Cancer 79: 173-179, 2013.

26. Xia JT, Wang H, Liang LJ, et al: Overexpression of FOXM1 is associated with poor prognosis and clinicopathologic stage of pancreatic ductal adenocarcinoma. Pancreas 41: 629-635, 2012.

27. Huang $\mathrm{H}$ and $\mathrm{He} \mathrm{X}$ : Wnt/beta-catenin signaling: new (and old) players and new insights. Curr Opin Cell Biol 20: 119-125, 2008.

28. Karayiannakis AJ, Syrigos KN, Polychronidis A and Simopoulos C: Expression patterns of alpha-, beta- and gamma-catenin in pancreatic cancer: correlation with E-cadherin expression, pathological features and prognosis. Anticancer Res 21: 4127-4134, 2001.

29. Lowy AM, Fenoglio-Preiser C, Kim OJ, et al: Dysregulation of beta-catenin expression correlates with tumor differentiation in pancreatic duct adenocarcinoma. Ann Surg Oncol 10: 284-290, 2003.

30. Pasca DMM, Biankin AV, Heiser PW, et al: Common activation of canonical Wnt signaling in pancreatic adenocarcinoma. PLoS One 2: e1155, 2007.

31. Zhang N, Wei P, Gong A, et al: FoxM1 promotes beta-catenin nuclear localization and controls Wnt target-gene expression and glioma tumorigenesis. Cancer Cell 20: 427-442, 2011.

32. Deer EL, Gonzalez-Hernandez J, Coursen JD, et al: Phenotype and genotype of pancreatic cancer cell lines. Pancreas 39: 425-435, 2010

33. Yang DD, Cui BB, Sun LY, et al: The co-expression of USP22 and BMI-1 may promote cancer progression and predict therapy failure in gastric carcinoma. Cell Biochem Biophys 61: 703-710 2011.
34. Wang H, Li YP, Chen JH, et al: Prognostic significance of USP22 as an oncogene in papillary thyroid carcinoma. Tumour Biol 34: 1635-1639, 2013.

35. Zhang Y, Yao L, Zhang X, et al: Elevated expression of USP22 in correlation with poor prognosis in patients with invasive breast cancer. J Cancer Res Clin Oncol 137: 1245-1253, 2011.

36. Hu J, Liu YL, Piao SL, Yang DD, Yang YM and Cai L: Expression patterns of USP22 and potential targets BMI-1, PTEN, p-AKT in non-small-cell lung cancer. Lung Cancer 77: 593-599, 2012.

37. Li J, Wang Z and Li Y: USP22 nuclear expression is significantly associated with progression and unfavorable clinical outcome in human esophageal squamous cell carcinoma. J Cancer Res Clin Oncol 138: 1291-1297, 2012.

38. Liu Y, Yang Y, Xu H and Dong X: Implication of USP22 in the regulation of BMI-1, c-Myc, p16INK4a, p14ARF, and cyclin D2 expression in primary colorectal carcinomas. Diagn Mol Pathol 19: 194-200, 2010.

39. Nagy Z, Riss A, Romier C, et al: The human SPT20-containing SAGA complex plays a direct role in the regulation of endoplasmic reticulum stress-induced genes. Mol Cell Biol 29: 1649-1660, 2009.

40. Nagy $Z$ and Tora L: Distinct GCN5/PCAF-containing complexes function as co-activators and are involved in transcription factor and global histone acetylation. Oncogene 26: 5341-5357, 2007.

41. Zhang XY, Pfeiffer HK, Thorne AW and McMahon SB: USP22, an hSAGA subunit and potential cancer stem cell marker, reverses the polycomb-catalyzed ubiquitylation of histone H2A. Cell Cycle 7: 1522-1524, 2008.

42. Atanassov BS and Dent SY: USP22 regulates cell proliferation by deubiquitinating the transcriptional regulator FBP1. EMBO Rep 12: 924-930, 2011.

43. Fu Z, Malureanu L, Huang J, et al: Plk1-dependent phosphorylation of FoxM1 regulates a transcriptional programme required for mitotic progression. Nat Cell Biol 10: 1076-1082, 2008.

44. Anders L, Ke N, Hydbring P, et al: A systematic screen for CDK4/6 substrates links FOXM1 phosphorylation to senescence suppression in cancer cells. Cancer Cell 20: 620-634, 2011.

45. Wang X, Bhattacharyya D, Dennewitz MB, et al: Rapid hepatocyte nuclear translocation of the Forkhead Box M1B (FoxM1B) transcription factor caused a transient increase in size of regenerating transgenic hepatocytes. Gene Expr 11: 149-162, 2003.

46. Wang IC, Chen YJ, Hughes D, et al: Forkhead box M1 regulates the transcriptional network of genes essential for mitotic progression and genes encoding the SCF (Skp2-Cks1) ubiquitin ligase. Mol Cell Biol 25: 10875-10894, 2005.

47. Allende-Vega N and Saville MK: Targeting the ubiquitinproteasome system to activate wild-type $\mathrm{p} 53$ for cancer therapy. Semin Cancer Biol 20: 29-39, 2010.

48. Clurman BE, Sheaff RJ, Thress K, Groudine M and Roberts JM: Turnover of cyclin $\mathrm{E}$ by the ubiquitin-proteasome pathway is regulated by cdk 2 binding and cyclin phosphorylation. Genes Dev 10: 1979-1990, 1996.

49. Bae Y, Choi D, Rhim H and Kang S: Hip2 interacts with cyclin B1 and promotes its degradation through the ubiquitin proteasome pathway. FEBS Lett 584: 4505-4510, 2010.

50. Pagano M, Tam SW, Theodoras AM, et al: Role of the ubiquitin-proteasome pathway in regulating abundance of the cyclin-dependent kinase inhibitor p27. Science 269: 682-685, 1995.

51. Ding GX, Liu J, Feng CC, Jiang HW, Xu JF and Ding Q: Slug regulates Cyclin D1 expression by ubiquitin-proteasome pathway in prostate cancer cells. Panminerva Med 54: 219-223, 2012.

52. Mandal S, Freije WA, Guptan P and Banerjee U: Metabolic control of G1-S transition: cyclin $\mathrm{E}$ degradation by $\mathrm{p} 53$-induced activation of the ubiquitin-proteasome system. J Cell Biol 188: 473-479, 2010.

53. Wang IC, Chen YJ, Hughes DE, et al: FoxM1 regulates transcription of JNK1 to promote the G1/S transition and tumor cell invasiveness. J Biol Chem 283: 20770-20778, 2008.

54. Nakamura S, Hirano I, Okinaka K, et al: The FOXM1 transcriptional factor promotes the proliferation of leukemia cells through modulation of cell cycle progression in acute myeloid leukemia. Carcinogenesis 31: 2012-2021, 2010.

55. Priller M, Poschl J, Abrao L, et al: Expression of FoxM1 is required for the proliferation of medulloblastoma cells and indicates worse survival of patients. Clin Cancer Res 17: 6791-6801, 2011 
56. He SY, Shen HW, Xu L, et al: FOXM1 promotes tumor cell invasion and correlates with poor prognosis in early-stage cervical cancer. Gynecol Oncol 127: 601-610, 2012.

57. Wierstra I and Alves J: FOXM1c transactivates the human c-myc promoter directly via the two TATA boxes P1 and P2. FEBS J 273: 4645-4667, 2006.

58. De Boer VC, de Goffau MC, Arts IC, Hollman PC and Keijer J: SIRT1 stimulation by polyphenols is affected by their stability and metabolism. Mech Ageing Dev 127: 618-627, 2006.

59. Zhu GY, Shi BZ and Li Y: FoxM1 regulates Sirt1 expression in glioma cells. Eur Rev Med Pharmacol Sci 18: 205-211, 2014.

60. Jiang L, Li J and Song L: Bmi-1, stem cells and cancer. Acta Biochim Biophys Sin (Shanghai) 41: 527-534, 2009.

61. Liu YL, Jiang SX, Yang YM, Xu H, Liu JL and Wang XS USP22 acts as an oncogene by the activation of BMI-1-mediated INK4a/ARF pathway and Akt pathway. Cell Biochem Biophys 62: 229-235, 2012.

62. Li SK, Smith DK, Leung WY, et al: FoxM1c counteracts oxidative stress-induced senescence and stimulates Bmi-1 expression. J Biol Chem 283: 16545-16553, 2008.

63. Katoh $\mathrm{M}$ and Katoh M: WNT signaling pathway and stem cell signaling network. Clin Cancer Res 13: 4042-4045, 2007.
64. Heiser PW, Lau J, Taketo MM, Herrera PL and Hebrok M: Stabilization of beta-catenin impacts pancreas growth. Development 133: 2023-2032, 2006.

65. Rulifson IC, Karnik SK, Heiser PW, et al: Wnt signaling regulates pancreatic beta cell proliferation. Proc Natl Acad Sci USA 104: 6247-6252, 2007.

66. Heiser PW, Cano DA, Landsman L, et al: Stabilization of beta-catenin induces pancreas tumor formation. Gastroenterology 135: 1288-1300, 2008.

67. Zhang Y, Morris JT, Yan W, et al: Canonical wnt signaling is required for pancreatic carcinogenesis. Cancer Res 73: 4909-4922, 2013.

68. Ripka S, Konig A, Buchholz M, et al: WNT5A - target of CUTL1 and potent modulator of tumor cell migration and invasion in pancreatic cancer. Carcinogenesis 28: 1178-1187, 2007.

69. Griesmann H, Ripka S, Pralle M, et al: WNT5A-NFAT signaling mediates resistance to apoptosis in pancreatic cancer. Neoplasia 15: 11-22, 2013.

70. Bowman A and Nusse R: Location, location, location: FoxM1 mediates beta-catenin nuclear translocation and promotes glioma tumorigenesis. Cancer Cell 20: 415-416, 2011. 